\title{
QUÍMICA DE (NANO)MATERIAIS
}

Aldo J. G. Zarbin

Departamento de Química, Universidade Federal do Paraná, CP 19081, 81531-990 Curitiba - PR, Brasil

(NANO)MATERIALS CHEMISTRY. An overview of different aspects related to Materials and Nanomaterials Chemistry is presented and discussed. The insertion of this field in Brazil is evaluated on the basis of the communications presented on the $30^{\text {th }}$ Annual Meeting of the Brazilian Chemical Society (SBQ). The importance of the Materials Chemistry Division of SBQ for the growth and consolidation of Materials Chemistry in Brazil is also discussed.

Keywords: materials chemistry; nanomaterials; Brazilian Chemical Society.

\section{INTRODUÇÃO}

Toda matéria é um material em potencial. A linha divisória para que algo possa ser tratado como um material corresponde ao momento em que alguma de suas propriedades (óticas, magnéticas, mecânicas, catalíticas, elétricas etc.) lhe confira uma função específica. Materiais podem ser definidos como "substâncias (ou mistura de substâncias) que possuem propriedades que as tornam úteis em produtos, dispositivos, estruturas e máquinas". . Nota-se que esta definição faz uma clara conexão entre materiais e utilidades.

A importância dos materiais na vida humana é tão significativa, que as diferentes eras do início da civilização foram definidas de acordo com a relação (e o domínio) do homem com os materiais: idade da pedra, do bronze, do ferro. A utilização de materiais para proteção, alimentação, vestimenta, moradia etc não só distingue a raça humana dos outros animais, como também garantiu (e garante) sua sobrevivência e ascendência sobre outras espécies. Nos dias de hoje, a utilização de diferentes materiais em absolutamente todas as atividades humanas é tão disseminada e abrangente que passa quase que desapercebida. Atividades simples e cotidianas, como acender uma lâmpada, ouvir um CD ou dirigir um automóvel, envolvem a utilização de um grande número de diferentes materiais, com as mais diversificadas propriedades. A utilização, o domínio, o desenvolvimento e a exploração de diferentes materiais têm uma profunda influência no desenvolvimento social e estão intimamente relacionadas a aspectos socioeconômicos, culturais, geográficos, demográficos, ambientais, dentre outros.

A relação entre "Química" e "materiais" é direta e inequívoca. A integração entre a perspectiva macroscópica que caracteriza os materiais (propriedades úteis para determinada função), com o enfoque atômico/molecular característico da Química (preparação, compreensão e estudo de reatividade de sólidos e moléculas) é imprescindível para o conhecimento e controle das conexões existentes entre estrutura, propriedades e funções de diferentes materiais. As relações entre aplicação, estrutura, propriedades e preparação estão esquematicamente ilustradas na Figura 1. Resumidamente, se estamos procurando um material para uma aplicação específica, deve-se compreender qual é a propriedade que o material deve possuir para que seja usado naquela aplicação. A partir disto, infere-se qual é a composição química e qual a estrutura do material capaz de fornecer a propriedade desejada e, finalmente, investiga-se qual a rota de preparação (síntese) capaz de produzir exatamente aquele material (com estrutura e composição química desejadas).

*e-mail: aldo@quimica.ufpr.br

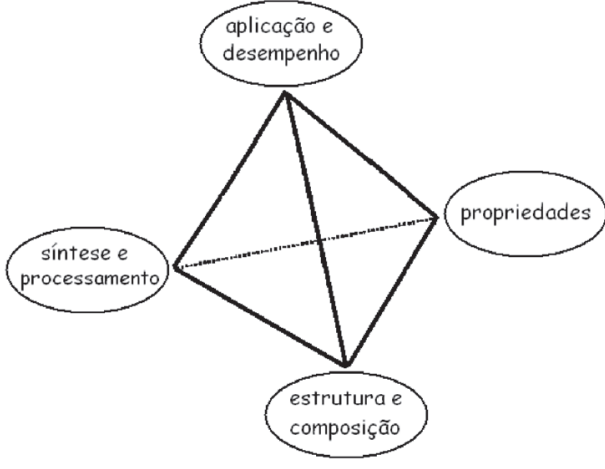

Figura 1. Relação entre aplicação, estrutura, propriedade e preparação de materiais

Dentre todos os ramos do conhecimento diretamente relacionados com materiais (Química, Física, Engenharias, Metalurgia, Geologia, Biologia, entre outros), a Química ocupa uma das posições mais importantes, localizando-se no centro da pirâmide esquematizada na Figura 1 e atuando como um ponto de confluência de cada um dos seus vértices. Nos últimos 20-25 anos, a chamada "Química de Materiais" saiu de uma situação periférica para se tornar um ramo emergente, com identidade própria e um ritmo de crescimento acelerado. A "Química de Materiais" pode ser definida como um ramo da Química que se dedica à síntese (preparação), caracterização, compreensão de propriedades e estudo de aplicações de compostos que possuem alguma função (ou que têm função em potencial). $\mathrm{O}$ foco deste ramo do conhecimento está centrado na utilização da Química, em toda a sua potencialidade, para criar, compreender e desenvolver compostos ou sistemas que podem levar ao desenvolvimento de novas oportunidades tecnológicas ou melhorias significativas em tecnologias já existentes.

A sistemática relacionada à Química de Materiais envolve quatro componentes essenciais: (I) síntese/preparação - que se caracteriza pela compreensão das reações químicas e metodologias que levam à produção de determinados materiais, estudo de diferentes reagentes e precursores, desenvolvimento de novas rotas de preparação e modificação e aprimoramento de rotas já existentes, otimização e planejamento de processos que levem à produção de diferentes materiais. Um controle sintético permite a obtenção de materiais com diferentes graus de pureza, cristalinidades e estruturas cristalinas, tamanhos de partículas, reatividades superficiais, além da produção de novos materiais, com composições e estruturas inéditas; (II) caracterização - que lança mão da utilização de 
técnicas químicas e físicas para compreensão de diferentes aspectos relacionados à composição (relação estequiométrica, presença de defeitos, estados de oxidação etc) e estrutura (amorfo ou cristalino, fase cristalina, ligações químicas etc) de materiais, além de interações específicas entre fases (para materiais multifásicos), tamanhos e formas de partículas etc; (III) estudo de propriedades e relação estrutura-propriedade - que visa a determinação das diferentes propriedades dos materiais (elétricas, óticas, magnéticas, catalíticas, mecânicas etc.), o mecanismo pelo qual estas propriedades se manifestam, e as relações existentes entre uma propriedade específica e a estrutura/composição do material; (IV) aplicações - que aproveita uma propriedade específica de um material para sua utilização como componente ativo em dispositivos, máquinas, sistemas etc. A combinação destas quatro linhas de trabalho leva a respostas para as questões básicas relacionadas a qualquer material: como são preparados? Como estão estruturados? Como se comportam? Qual sua utilidade? Onde podem ser empregados?

A relação íntima entre a Química e os materiais é muito mais antiga que a própria Química (enquanto um ramo independente da ciência). A descoberta de que metais poderiam ser produzidos a partir de rochas minerais, os primeiros relatos de preparação de vidros e a obtenção de papel a partir da madeira são alguns dos muitos exemplos desta constatação. Entretanto, apesar desta relação antiga, a existência e o reconhecimento da "Química de Materiais" como uma subdivisão da Química é relativamente recente. Durante muito tempo, as chamadas "Ciências dos Materiais" concentravam-se fundamentalmente nos aspectos macroscópicos dos materiais (propriedades), ficando predominantemente restritas aos diferentes ramos das Engenharias. O crescente aparecimento de materiais novos e sofisticados, com propriedades cada vez mais surpreendentes, aliado ao desenvolvimento de novas técnicas de análise e caracterização (espectroscopias, microscopias etc.), acarretou em uma aproximação cada vez maior entre a Química e as Ciências dos Materiais. A identidade da Química de Materiais estabeleceu-se permanentemente entre os anos de 1980-1990, e teve o seu ápice quando as duas sociedades científicas de Química mais tradicionais do mundo, a americana "American Chemical Society (ACS)" e a inglesa "Royal Society of Chemistry (RSC)", lançaram periódicos específicos nesta área, respectivamente, o "Chemistry of Materials" e o "Journal of Materials Chemistry". A capa frontal do primeiro número do Journal of Materials Chemistry apresentava o seguinte texto: "uma revista interdisciplinar relacionada à síntese, estrutura, propriedades e aplicações de materiais, particularmente aqueles associados com tecnologia avançada"2. A ocorrência destas iniciativas fez com que químicos que trabalhavam com os diferentes aspectos relacionados a materiais, e que estavam dispersos em outras subdivisões da Química, pudessem encontrar sua comunidade e começar a uniformizar sua linguagem.

A relevância da Química de Materiais nos dias atuais é inconteste. Os dois periódicos citados anteriormente possuem altos índices de impacto, publicam artigos de alta relevância provenientes de grupos de pesquisa dispersos por todos os continentes e fazem parte das publicações mais importantes das respectivas sociedades; os principais periódicos específicos de Química Inorgânica e Físico-Química têm seções totalmente voltadas para a Química de Materiais; novos periódicos foram lançados em praticamente todas as editoras científicas, direcionados direta ou indiretamente à Química de Materiais; a divisão de Físico-Química da ACS criou, em 2007, o Journal of Physical Chemistry C, (nanomaterials and interfaces), totalmente dedicado à síntese e caracterização de nanomateriais e nanoestruturas; cursos de Química de Materiais são oferecidos em praticamente todos os institutos e departamentos de Química de grandes universidades, em nível de graduação e pós- graduação; em abril de 2006 a RSC promoveu o workshop "Defining Materials Chemistry"3, com os objetivos de promover definições e discussões relacionadas a este tópico, justificado pela rapidez com que a disciplina cresceu nos últimos 15 anos e pela constatação de que uma parcela significativa de todas as publicações em Química tem sido considerada como pertencente à área; em 2005, a IUPAC criou uma força-tarefa de 2 anos, visando definições em Química de Materiais. O objetivo deste projeto é "produzir uma definição de como a Química de Materiais pode ser enquadrada dentro da estrutura organizacional geral da IUPAC" ${ }^{4}$, justificada pelo crescimento vigoroso da área e pela necessidade de se estabelecer critérios e definições.

A Química de Materiais é uma área claramente inter- e multidisciplinar, que integra conhecimentos e habilidades das quatro divisões clássicas da Química e cruza as fronteiras entre a Química e a Física, a Química e a Biologia, a Química e as Engenharias. Algumas de suas especificidades, alguns exemplos, o contexto onde está inserida no Brasil e a contribuição da Sociedade Brasileira de Química (SBQ) em seu desenvolvimento serão tópicos abordados a seguir.

\section{QUÍMICA DE MATERIAIS E A QUÍMICA DOS MATERIAIS}

Do ponto de vista da Engenharia e das Ciências dos Materiais, pode-se classificar os materiais em cinco diferentes categorias, de acordo com algumas de suas estruturas ou propriedades mais características: metais, polímeros, cerâmicas, semicondutores e compósitos ${ }^{5}$.

Materiais metálicos são constituídos de elementos metálicos (puros ou em combinação, originando as chamadas ligas metálicas), como ferro, cobre, aço, bronze etc. Possuem elétrons deslocalizados em sua estrutura e caracterizam-se pela alta condutividade elétrica e térmica, brilho, maleabilidade, ductibilidade e resistência mecânica. São classicamente utilizados como fios condutores (cobre), materiais para sustentação na construção civil (aço), na indústria automobilística, em utensílios domésticos etc.

Polímeros são compostos macromoleculares, de origem natural ou sintética, formados pela repetição de um grande número de unidades químicas estruturais (meros). Podem ser inorgânicos ou orgânicos, embora estes últimos predominem em termos de aplicações comerciais. Plásticos, borrachas, celulose, diferentes classes de silicones e vários tipos de adesivos fazem parte dos materiais poliméricos. Normalmente estes materiais apresentam baixas condutividades elétrica e térmica, têm baixa resistência mecânica e não podem ser utilizados para aplicações que requeiram altas temperaturas. Trata-se de uma das classes de materiais mais utilizadas em aplicações diversas, como embalagens, adesivos, componentes de automóveis, em circuitos integrados, fibras para vestimentas etc.

Cerâmicas são compostos fundamentalmente inorgânicos, como óxidos, sulfetos, nitretos, carbetos, silicatos, carbonatos. São geralmente isolantes térmicos e elétricos, apresentam altas resistências térmica e química, alta dureza, mas são materiais quebradiços. Os vidros fazem parte deste grupo de materiais. As cerâmicas são utilizadas como materiais refratários, em embalagens e janelas de vidros, fibras óticas etc.

Semicondutores apresentam condutividade elétrica intermediária entre os metais e os isolantes, e mecanismo de condução diferenciado dos metais. Exemplos de semicondutores são silício, germânio, $\mathrm{CdS}, \mathrm{GaAs}$ etc. São materiais essenciais em aplicações eletrônicas, em computadores e tecnologia de comunicação, responsáveis pelo advento dos transistores, diodos e circuitos integrados, que revolucionaram a indústria eletrônica a partir da década de 60 .

Compósitos são materiais formados pela combinação de dois ou mais diferentes materiais, produzindo propriedades únicas e 
sinergísticas, diferentes daquelas de seus componentes individuais. Concreto, madeira, tintas e fibras de vidro são exemplos de materiais compósitos.

Apesar das definições sumarizadas anteriormente serem amplamente utilizadas por vários cientistas de materiais (incluindo químicos), elas falham em uma série de situações, principalmente quando se tratam de materiais novos e avançados. Um exemplo notável refere-se aos chamados polímeros condutores, uma classe de polímeros orgânicos que apresentam condutividade elétrica comparável à dos semicondutores ou mesmo à de alguns metais. Estes materiais, de elevada relevância científica e tecnológica (a descoberta desta classe de polímeros, em 1977, acarretou aos cientistas responsáveis o Prêmio Nobel de Química de 2000), pertencem tanto à classe dos materiais poliméricos quanto à dos semicondutores, sendo conhecidos como semicondutores orgânicos. Vários outros exemplos de materiais cujas classificações não são perfeitamente compatíveis a uma das categorias classicamente utilizadas podem ser encontrados, e o advento dos nanomateriais e dos materiais nanoestruturados (que serão discutidos a posteriori) contribuiu bastante para esta realidade. Alguns pesquisadores têm adotado uma classificação um pouco diferenciada para os materiais, que seriam divididos nas seguintes categorias ${ }^{6}$ : metais e ligas metálicas, materiais inorgânicos; materiais orgânicos; materiais biológicos; compósitos. Esta última classificação parece mais abrangente e capaz de contemplar, de forma mais contundente, um número mais elevado de diferentes materiais.

Dada sua heterogeneidade e complexidade, a Química de Materiais engloba uma formação multidisciplinar e o conhecimento de diferentes tópicos, como alguns dos listados a seguir: i) natureza da ligação química e de forças intermoleculares; ii) química do estado sólido, cristalografia, estrutura de sólidos cristalinos e amorfos, defeitos, não-estequiometria, transições de fase, diagramas de fase; iii) termodinâmica; iv) cinética; v) teoria de bandas, estrutura eletrônica de sólidos, condutividade (eletrônica e iônica) em sólidos; vi) síntese de materiais: métodos de preparação de materiais inorgânicos; vii) síntese, caracterização, propriedades e processamento de polímeros, monômeros e precursores (orgânicos e inorgânicos, como compostos organometálicos e metalorgânicos, por exemplo); viii) química coloidal, estabilidade coloidal, química de superfícies, interações superficiais, tensão superficial, adesão; ix) magnetismo; x) espectroscopia; xi) eletroquímica, xi) interações radiação/matéria e fundamentos de técnicas de caracterização (microscopia eletrônica, técnicas de difração, técnicas espectroscópicas, técnicas eletroquimicas etc.); xii) tensão, fratura de sólidos, fadiga, dureza; xiii) nanociência e nanotecnologia - síntese e caracterização de nanomateriais, nanopartículas, nanocompósitos, compreensão de efeitos quânticos de tamanho; síntese com controle de tamanho e forma; xiv) "design" de dispositivos e sistemas, reciclagem.

Até muito recentemente, não se encontrava a possibilidade de uma formação onde todos estes tópicos (e vários outros, de relevância tão significativa) eram direcionados para um objetivo comum. Os currículos clássicos dos cursos de Química, tanto na graduação quanto na pós-graduação, posicionam cada um destes tópicos dispersos nas quatro grandes áreas da Química (Química Orgânica, Química Inorgânica, Química Analítica e Físico-Química), sendo que alguns deles (nanociência e nanotecnologia, por exemplo) ainda não são tratados em cursos universitários de muitas instituições. $\mathrm{O}$ advento de vários cursos de pós-graduação contendo a Química de Materiais como linha de pesquisa contribuiu para uma redução deste efeito. Alguns avanços na melhoria da formação de químicos com um maior conhecimento na área de Química de Materiais, também no nível da graduação, vêm sendo detectados através da introdução de algumas disciplinas específicas para este perfil. Chamam a atenção esforços dife- renciados, como o recentemente desenvolvido pela Universidade da Califórnia, que criou um programa interdisciplinar de 2 anos, chamado de "Materials Creation Training Program", visando uma formação suplementar (e em paralelo) para estudantes regulares de graduação (das áreas de química, física e engenharia), totalmente voltado para a formação de cientistas de materiais, onde vários dos tópicos listados anteriormente, juntamente com conceitos de Física e Engenharia de Materiais, são trabalhados em conjunto ${ }^{7}$.

$\mathrm{O}$ advento da Química de Materiais (assim como da nanociência e nanotecnologia e de outros ramos da Química, Física e Biologia) constitui-se em um dos muitos avanços no sentido de desmoronar dois grandes entraves no desenvolvimento da formação e do conhecimento científico e tecnológico: a fragmentação e compartimentalização do conhecimento em áreas, subáreas e disciplinas, que trabalham de forma estanque e isolada, restringindo uma visão global e tornando interfaces entre áreas de conhecimento pouco (ou nada) exploradas, e a separação absolutamente artificial e arcaica entre ciência básica e ciência aplicada. Com relação a este último ponto, temos no Brasil um exemplo recente e admirável, representado pelo lançamento mundial, pelo grupo Bunge, do pigmento Biphor (constituído de nanopartículas ocas de fosfato de alumínio, que substitui o $\mathrm{TiO}_{2}$ classicamente utilizado como pigmento branco), que foi totalmente desenvolvido no laboratório do Prof. Fernando Galembeck, na Unicamp ${ }^{8}$. Este produto é resultante de um trabalho que se iniciou como pesquisa acadêmica e tem um mercado total estimado de US\$ 5 bilhões por $\mathrm{ano}^{9}$. A empresa fabricante, que investiu cerca de R\$ 1 milhão durante os nove anos de desenvolvimento do produto com a Unicamp, prevê alcançar participação de $10 \%$ no mercado em 4 anos 9 .

Com a Química de Materiais, o químico trouxe novas ferramentas para sua bancada de trabalho (tradicionalmente ocupada por atividades sintéticas): caracterizações estruturais e morfológicas, medidas de propriedades físicas e estudos de aplicações de materiais. Entretanto, deve-se deixar claro que o grande diferencial do Químico de Materiais, em relação a qualquer outro cientista de materiais, é exatamente o que diferencia a Química de todas as outras áreas do conhecimento: a capacidade de manipular e transformar a matéria (ou seja, síntese), com reprodutibilidade e controle de rendimento e pureza (e no caso específico de sólidos, com controle de tamanho e forma de partículas e, ainda, homogeneidade estrutural). Um controle nas propriedades requer um fino controle em todas as variáveis de síntese. A aplicabilidade de um material só pode ser imaginável quando sua produção pode ser realizada de forma reprodutível. E nestas habilidades, o químico é insubstituível!

A sistemática de trabalho do Químico de Materiais, no que diz respeito somente à síntese, envolve um amplo espectro de possibilidade: busca pela síntese de um novo material, ou seja, de um material que realmente ainda não existe, com composição e/ou estrutura inédita, ou ainda compósitos inéditos, formados por combinações binárias, ternárias etc de materiais, como por exemplo os vários novos (nano)compósitos formados entre diferentes polímeros e nanotubos de carbono ${ }^{10}$; desenvolvimento de novas rotas de síntese para materiais "tradicionais", com vantagens sobre as rotas tradicionalmente utilizadas, visando, por exemplo, baratear custos, aumentar a pureza e homogeneidade do material sintetizado, aumentar a segurança do processo, aumentar a escala de produção, tornar a síntese ambientalmente amigável etc. O processo sol-gel ${ }^{11}$, que permitiu a síntese de vidros e cerâmicas a partir de precursores moleculares com alta pureza, baixo gasto energético e possibilidade de modificações químicas ou estruturais inimagináveis quando da utilização dos métodos clássicos de formação destes materiais (fusão e resfriamento de óxidos ou reações no estado sólido), é um bom exemplo desta vertente; desenvolvimento de rotas de síntese para materiais com controle de tamanho e forma de partículas, como 
os diferentes aspectos relacionados à nanoquímica, que serão discutidos a seguir; síntese de novos precursores para materiais, como por exemplo novos alcóxidos para serem utilizados como precursores no processo sol-gel ${ }^{12}$; síntese de materiais na forma de filmes, fibras, monólitos, para aplicações específicas; síntese in situ de materiais diretamente sobre sistemas, para fabricação de dispositivos; síntese de materiais usando matéria-prima renovável, ou modificações em rejeitos visando aplicações específicas; reciclagem de materiais; modificações estruturais em materiais, como reações de intercalação e de troca-iônica; reações de modificação de superfícies de materiais; síntese de materiais visando a substituição, em aplicações diversas, de materiais correntemente em uso etc.

Outra peculiaridade inerente à sistemática de trabalho do Químico de Materiais é a utilização de grandes e médios equipamentos, para a caracterização adequada dos materiais preparados. Técnicas espectroscópicas (infravermelho, Raman, UV-Vis, NMR, RPE, Mössbauer, luminescência, EELS etc), técnicas de difração (raios $\mathrm{X}$, elétrons, nêutrons etc), técnicas térmicas (TGA, DSC, DTA etc), técnicas de superfície (XPS, ESCA, Auger, BET, porosimetria etc.), técnicas de microscopia eletrônica (MET, MEV), técnicas de microscopia de sonda (AFM, SPM etc.), técnicas envolvendo radiação síncrotron (EXAFS, XANES, difração, SAXS etc.), técnicas envolvendo espalhamento de luz (DLS etc), técnicas eletroquímicas (voltametria cíclica, impedância etc.), técnicas envolvendo medidas elétricas (quatro pontas etc), dentre muitas outras, fazem parte da caixa de ferramentas do químico de materiais (juntamente com o arsenal de possibilidades relacionadas à síntese, descritas no parágrafo anterior). Um entendimento aprofundado das técnicas de caracterização (no que diz respeito aos conceitos físico-químicos e teóricos envolvidos, à forma de coleta dos dados e à correta interpretação dos mesmos), o discernimento sobre qual técnica utilizar para resolver qual tipo de problema, a correlação entre os resultados obtidos por cada técnica e as singularidades do material em estudo e, fundamentalmente, um amplo conhecimento da complementaridade existente entre cada técnica são características esperadas de um bom Químico de Materiais.

Um aspecto importante que merece ser considerado é a definição do que é um material "novo" e o que é um material "tradicional". Logicamente que qualquer material de criação recente, e que não existia há algum tempo, é um novo material. Entretanto, outro tipo de enfoque deve ser também considerado para a diferenciação entre materiais novos e tradicionais ${ }^{13}$ : a taxa de mudança e de incorporação de inovações associada ao material em questão. O novo é aquele que permitiu inovações em altas taxas. Desta forma, a descoberta de novas propriedades (ou novas aplicações) para um material conhecido há milênios faz deste um novo material. Por exemplo, óxido de ferro é um material antigo (em termos cronológicos), mas cada vez mais novo, dada a grande quantidade de novas propriedades, novas aplicações e novas utilizações que correntemente são descritas para este material (ou em outras palavras, dada a alta taxa de inovação associada).

Nos últimos anos, nenhuma classe de materiais tem despertado tanto interesse quanto os materiais obtidos em escala nanométrica de tamanho - os nanomateriais.

\section{NANOMATERIAIS}

O estudo de materiais cujos tamanhos das partículas que os constituem encontram-se na faixa dos nanômetros (chamados de nanomateriais) ganhou importância significativa no final do século $\mathrm{XX}$, levando ao aparecimento e consolidação de toda uma área do conhecimento, hoje reconhecida como "Nanociência e Nanotecnologia". De fato, nos primeiros anos do século XXI é raro encontrar pessoas que de alguma forma nunca tenham se deparado com estes termos. A área da Nanociência e Nanotecnologia extrapolou os limites da academia e da indústria e, rapidamente, atingiu o público em geral, trazendo consigo promessas de uma verdadeira revolução de costumes, alimentando a imaginação da indústria da ficção científica.

De maneira direta, podemos apoiar a Nanociência e Nanotecnologia sobre um grande alicerce: o fato de que as propriedades dos materiais, da maneira pela qual as conhecemos, são fortemente dependentes do tamanho das partículas deste material. Em outras palavras, todas as propriedades dos materiais (óticas, elétricas, magnéticas, de transporte, catalíticas etc), da forma pela qual as conhecemos, manifestam-se a partir de um determinado tamanho, chamado de crítico. Quando as partículas deste material estão abaixo deste tamanho crítico, esta propriedade se torna diferenciada. Para um mesmo material, freqüentemente o tamanho crítico é diferente para cada uma das suas propriedades (por exemplo, o tamanho crítico para propriedades óticas de um determinado nanomaterial pode ser $20 \mathrm{~nm}$, enquanto que para as propriedades magnéticas pode ser $80 \mathrm{~nm}$ ). Para uma mesma propriedade, o tamanho crítico é diferente para diferentes materiais. Além disso, quando abaixo do tamanho crítico, as propriedades do material dependem também da forma das partículas, ou seja, nanopartículas esféricas com diâmetro de $5 \mathrm{~nm}$ têm propriedades diferentes daquelas encontradas para o mesmo material, mas com nanopartículas na forma de bastão com $5 \mathrm{~nm}$ de comprimento.

Estas considerações nos transportam para uma realidade extremamente excitante: novos materiais, com novas propriedades e possibilidades de utilização, podem ser preparados através do controle do tamanho e da forma das partículas de materiais já conhecidos. Este efeito de tamanho é característico da matéria e se manifesta devido a vários motivos, cujos detalhamentos não fazem parte dos objetivos deste texto. A alta razão superfície/volume e o fato de que os portadores de carga, em nanomateriais, ficam confinados nas dimensões reduzidas das partículas, são alguns dos fatores que contribuem para esta realidade. Desta forma, todas as classes de materiais (metais, semicondutores, cerâmicas, polímeros, compósitos) podem ter suas propriedades moduladas sem que se altere sua composição química e/ou estrutura tridimensional, mas única e tão somente pelo controle do tamanho e formato de suas partículas. A Nanociência e Nanotecnologia levou a uma grande mudança de paradigma nas ciências dos materiais: um dos vértices da pirâmide representada na Figura 1 foi modificado. Para se obter a propriedade desejada deve-se procurar não só a composição química e a estrutura do material (como representado na Figura 1), como também o tamanho e o formato de suas partículas.

Desta forma, podemos definir nanomateriais como sendo materiais que possuem ao menos uma dimensão na faixa de tamanho nanométrica, abaixo do tamanho crítico capaz de alterar alguma de suas propriedades. Em muitos dos textos recentes sobre Nanociência e Nanotecnologia costuma-se arbitrar valores fronteiriços para as dimensões de um nanomaterial, por exemplo, até 100 nm. Este procedimento é absolutamente equivocado. Só existe um nanomaterial se existir uma propriedade que se manifesta exclusivamente devido ao tamanho reduzido, e esta propriedade é diferente do material massivo. Da mesma forma, não basta um material ter dimensões nanoméricas para ser considerado um nanomaterial. Por exemplo, se temos um composto contendo partículas esféricas de $200 \mathrm{~nm}$, mas todas as propriedades deste composto têm tamanhos críticos inferiores a $150 \mathrm{~nm}$ (portanto este material está acima do tamanho crítico de todas as suas propriedades), este não é considerado um nanomaterial, apesar de ter partículas em dimensões nanométricas. Da mesma forma, a Química de nanomateriais corresponde à extrapolação daquilo que se entende por Química de 
Materiais, mas com o enfoque único e tão somente voltado para os nanomateriais. O termo "nanoquímica" foi cunhado com sucesso, para definir a utilização de todo o conhecimento, prática e ferramentas da Química para preparar, caracterizar, estudar propriedades e aplicações de nanomateriais em diferentes tamanhos, formas, composições, estruturas, cargas e funcionalidades, com rigoroso controle de cada um destes parâmetros.

Nanopartículas são termodinamicamente instáveis e têm a tendência natural de se agregarem e crescerem. Desta forma, o grande desafio do Químico de Materiais consiste exatamente em preparar nanomateriais estáveis (ou seja, que permaneçam nesta escala de tamanho sem sofrer decomposição e sem agregação e crescimento) e monodispersos, tanto com relação ao tamanho quanto com relação à forma de suas partículas, que possam ser manipulados, dispersos, depositados sobre substratos, sem perder suas características. Este é um campo extraordinariamente fértil, onde a criatividade do Químico de Materiais, e do químico sintético de maneira geral, é o grande diferencial. Novas rotas de síntese para os mais diferentes nanomateriais (e o preparo de diferentes nanomateriais através de adaptações em rotas já conhecidas) são descritas a todo o momento na literatura, juntamente com a descoberta de novas propriedades e novas possibilidades de aplicação.

O controle rigoroso sobre os processos de síntese de nanomateriais, levando à produção reprodutível de amostras com alto grau de homogeneidade, corresponde a um dos grandes fatores responsáveis pelo crescimento vertiginoso da Nanociência e Nanotecnologia. Sólidos com tamanhos de partículas nanométricas são considerados como espécies intermediárias entre moléculas individuais e o sólido massivo ("bulk"), apresentando fenômenos e propriedades diferenciadas e características deste estado "embrionário". A compreensão destes fenômenos, assim como a utilização das diversas propriedades decorrentes dos mesmos, só é possível se o material puder ser obtido de forma homogênea, controlada e reprodutível, exatamente da forma pela qual o Químico de Materiais vem trabalhando.

Um outro fator responsável pelo crescimento desta área é o grande desenvolvimento das técnicas de caracterização, principalmente as técnicas de microscopia. O surgimento de microscópicos com resolução atômica, cada vez mais sensíveis e potentes, acoplados aos mais criativos e surpreendentes acessórios, assim como a utilização das outras técnicas de caracterização no limite das suas potencialidades, permitiu o acesso ao mundo nanoscópico num grau de detalhamento inimaginável há 30 ou 40 anos atrás.

Dentre os vários materiais que podem ser enquadrados na classe dos nanomateriais, os nanotubos de carbono talvez sejam os mais representativos. Nanotubos de carbono são materiais verdadeiramente novos, em qualquer um dos aspectos analisados: são novos no que diz respeito à idade (foram descritos pela primeira vez em $1991^{14}$, embora sua existência já tivesse sido detectada anteriormente ${ }^{15}$, sem o grau de detalhamento e importância do trabalho de 1991); são novos por apresentarem um conjunto de propriedades novas (algumas até então desconhecidas), diferenciadas e singulares; são novos pelo aspecto da aplicação, pois podem ser utilizados em um grande número de sistemas, desde sensores de gases até reforço em polímeros (novas aplicações - reais ou em potencial para nanotubos de carbono têm sido constantemente relatadas na literatura recente); são novos porque apresentam uma altíssima taxa de inovação associada.

Um nanotubo de carbono (CNT) caracteriza-se pelo enrolamento de uma ou várias folhas de grafeno de forma concêntrica, com diâmetro em dimensões nanométricas, com cavidade interna oca, conforme mostrado esquematicamente na Figura 2 (uma folha de grafeno consiste em um arranjo bidimensional formado por hexágonos de átomos de carbono $\mathrm{sp}^{2}$, cujo empilhamento origina a estrutura do grafite). Os CNTs podem ser divididos em dois grupos: os CNTs de camada única ("SWCNTs - "single-walled carbon nanotubes"), Figura 2a, e os CNTs de camadas múltiplas ("MWCNTs - multi-walled carbon nanotubes"), Figura $2 b^{17}$. Os MWCNTs são constituídos de 2 a 40 camadas de grafeno concêntricas, que se distanciam entre si por $0,34 \mathrm{~nm}$ (de maneira análoga à separação existente entre os planos (002) do grafite) e normalmente apresentam diâmetros de 10 a $50 \mathrm{~nm}$ com comprimentos maiores que 10 micrometros, sendo que suas propriedades estão diretamente ligadas ao número de camadas e ao seu diâmetro interno. Os SWCNTs são mais finos e apresentam diâmetro variando entre 1 e $5 \mathrm{~nm}$, sendo formados por uma única folha de grafeno.
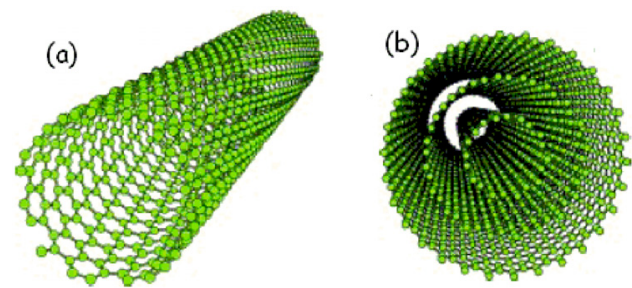

Figura 2. Representação esquemática da estrutura de nanotubos de carbono. (a) nanotubo de parede simples, (b) nanotubo de parede múltipla

A simetria dos CNTs é dada pela maneira como a folha de grafeno se enrola. Desta forma, os SWCNTs podem apresentar três diferentes estruturas quirais: "armchair", "zig-zag" e "chiral"16.

Nanotubos de carbono são considerados materiais estratégicos e com um grande número de possibilidade de aplicações tecnológicas, devido às suas propriedades bastante intrigantes. Além de uma alta resistência química, resistência à oxidação e à temperatura e baixa densidade, os nanotubos de carbono apresentam propriedades muito distantes das usuais: no que diz respeito ao transporte elétrico, podem apresentar características metálicas, semicondutoras ou até supercondutoras, de acordo com sua estrutura (SWCNT ou MWCNT), diâmetro e quiralidade; como a ligação C-C em estruturas grafíticas é uma das mais fortes da natureza, os CNTs representam uma das estruturas mais robustas conhecidas, com altíssima resistência mecânica, flexibilidade e resistência à ruptura quando dobrados ou torcidos ${ }^{17}$. Este conjunto fantástico de propriedades, decorrentes fundamentalmente da escala de tamanho destes materiais, faz com que nanotubos de carbono venham sendo utilizados nas mais diversas aplicações (muitas delas com produtos já disponíveis comercialmente), dentre as quais podemos citar algumas: como emissores de elétrons para televisores; como sensores de gases e sensores biológicos; em pontas de AFM; em compósitos com polímeros, cerâmicas e metais (visando materiais com alta resistência mecânica); em dispositivos eletrônicos; em diodos; em transistores; em baterias de íons lítio; em células a combustível; em dispositivos fotovoltaicos; em memórias de computador; em lâmpadas; em supercapacitores; em dispositivos para armazenar hidrogênio; em novos dispositivos para medicina etc.

Existem alguns métodos de preparação de CNTs. Dentre eles, o método mais promissor é um método químico, chamado de decomposição catalítica de hidrocarbonetos ${ }^{16}$. O método consiste na pirólise de um precursor de carbono (normalmente um hidrocarboneto como metano, etileno, benzeno, xileno), em atmosfera inerte e condições adequadas de temperatura, taxa de aquecimento e atmosfera. Além disso, para a formação de CNTs é fundamental a presença de catalisadores metálicos (como $\mathrm{Fe}, \mathrm{Co}, \mathrm{Ni}$ ), cujas partículas atuam como nucleantes ${ }^{16}$. Neste caso, as características do catalisador metálico são diretamente responsáveis pela qualidade dos nanotubos 
formados. Propriedades como diâmetro dos tubos, grau de pureza e grafitização, tipo do nanotubo (SWCNT ou MWCNT), dentre outras, são fortemente dependentes do tipo, qualidade e distribuição das partículas do catalisador. Os diâmetros dos nanotubos, por exemplo, serão aproximadamente os mesmos diâmetros das nanopartículas utilizadas como catalisadores.

Apesar dos avanços observados nos últimos anos, a síntese de nanotubos de carbono ainda é um campo a ser explorado, com grandes desafios a serem vencidos, no que diz respeito à obtenção de amostras com alta pureza, com distribuição homogênea de diâmetros, contendo somente SWCNTs ou MWCNTs, com alto controle da quiralidade (somente CNTs "armchair" ou somente "chiral"), com alto grau de alinhamento dos nanotubos uns em relação aos outros (fundamental para uma série de aplicações, dado ao caráter anisotrópico destes materiais), com alto rendimento e taxa de produção elevada, e com baixo custo! O método de decomposição catalítica de hidrocarbonetos vem sendo apontado como o único capaz de atender a todas estas exigências e a Química de Materiais tem papel crucial nesta direção.

Vários tipos de nanomateriais, como os nanotubos de carbono, nanopartículas metálicas, nanopartículas de óxidos de metais de transição, nanoemulsões e os mais diferentes tipos de nanocompósitos, já saíram dos laboratórios acadêmicos e podem ser encontrados como componentes ativos em uma série de produtos atualmente no mercado. $\mathrm{O}$ mercado mundial para produtos à base de nanotecnologia, estimado para o ano de 2010, é de 11 trilhões de dólares americanos ${ }^{18}$, sendo que 340 bilhões correspondem somente a nanomateriais (catalisadores para automóveis, materiais para gravação magnética e componentes para protetores solares são os itens mais produzidos atualmente $\left.{ }^{18}\right)$. $\mathrm{O}$ investimento governamental em pesquisa e desenvolvimento para nanotecnologia (sendo que nanomateriais envolve a maior fração dos recursos), somente no ano de 2005, foi de US\$1,08 bilhões pelos Estados Unidos, US\$1,05 bilhões pela comunidade européia, US\$ 950 milhões pelo Japão, e cerca de US\$ 1 bilhão pelos outros países do mundo ${ }^{19}$. Somente com os dados disponíveis (certamente incompletos e bem inferiores aos reais), estima-se que neste mesmo ano o investimento em pesquisa e desenvolvimento na área de nanotecnologia feito por indústrias foi próximo de US\$3,8 bilhões, sendo $46 \%$ por empresas americanas, $36 \%$ por asiáticas, $17 \%$ por européias e $1 \%$ por empresas dos outros paises do mundo ${ }^{19}$. A indústria Química (incluindo petroquímica), as indústrias relacionadas a bens de consumo (incluindo indústria cosmética), a materiais (incluindo metalúrgica), a semicondutores, a comunicações, a transportes (incluindo aeronáutica e aeroespacial) e a indústria biomédica/ farmacêutica correspondem à grande maioria destes investimentos ${ }^{19}$. A estimativa é que os investimentos governamentais se mantenham neste mesmo patamar anual até 2010, enquanto que os investimentos privados devam duplicar até este mesmo $\mathrm{ano}^{21}$.

Dentre as grandes empresas que estão com investimento pesado na área de nanomateriais, e que já têm produtos no mercado, destacam-se algumas gigantes químicas, como Dow Chemical, BASF, 3M, Dupont, Bayer, Merck, Bunge, dentre outras. No ano de 2002 a indústria química norte americana criou um "workshop" permanente intitulado "Chemical Industry Vision 2020", com a participação de mais de 150 empresas, em parceria com órgãos do governo e sociedades cientificas, como a $\mathrm{ACS}^{21}$. Os objetivos foram definir prioridades em pesquisa e desenvolvimento de nanomateriais considerados estratégicos para a indústria química e de materiais. Foram listadas 30 prioridades de ação em 9 categorias (conhecimento fundamental e síntese; manufatura e processamento; técnicas de caracterização; simulação e modelagem; meio ambiente, saúde e segurança; metrologia e informática; transferência de tecnologia; educação; infra-estrutura e recursos disponíveis), com perspectiva de investimentos a curto, médio e longo prazos e recomendações específicas voltadas para um único objetivo: acelerar a comercialização de novas tecnologias baseadas em nanomateriais ${ }^{21}$. Em março de 2006 este mesmo consórcio da indústria química americana, em parceria com o laboratório nacional de Los Alamos e o Departamento de Energia do governo, publicou um estudo intitulado "Estimativa de Economia de Energia e Impactos Financeiros na Utilização de Nanomateriais em Aplicações Selecionadas na Indústria Química"22. Este estudo estimou o impacto de apenas três tipos de nanomateriais (catalisadores, filmes nanométricos para recobrimentos e membranas nanoporosas) na economia de energia, competitividade econômica, redução de rejeitos e produtividade de indústrias químicas e correlatas. Os resultados indicaram, por exemplo, que é possível uma economia de US\$2,5 a US\$ 4 bilhões por ano pela diminuição nos custos da produção somente pela substituição de catalisadores convencionais por nanocatalisadores, além de uma economia energética de 200 a 400 trilhões de BTU/ano na produção. Estes números aumentariam, em 3 anos, algo em torno de US\$ 10 a 15 bilhões na participação da indústria química no PIB americano, possibilitando a geração de 150.000 a 240.000 novos postos de trabalho neste mesmo período de tempo ${ }^{22}$.

As considerações e os números demonstrados nos últimos parágrafos não deixam dúvidas quanto à importância e participação crescente que os nanomateriais terão em nosso cotidiano. Trata-se de uma jornada de mão única, onde a Química é, sem sombra de dúvida, uma das principais condutoras.

\section{A QUÍMICA DE (NANO)MATERIAIS NO BRASIL}

A Sociedade Brasileira de Química (SBQ) teve um papel fundamental na consolidação da identidade de Química de Materiais no Brasil, quando da criação da Divisão de Química de Materiais (DQM), que apresentou a primeira sessão de trabalhos na Reunião Anual da SBQ de 1993, agregando os trabalhos de Química de Materiais que tradicionalmente se encontravam dispersos em várias outras Divisões. A criação da DQM atendeu aos anseios de químicos que desenvolviam seus trabalhos na área de materiais, criando um foro adequado para discussão conjunta das diversas peculiaridades da área, e rumando na direção dos ventos mundiais, que já estavam considerando a área de Química de Materiais como uma subárea relevante da Química. Atualmente a DQM corresponde a uma das maiores divisões da SBQ, seja em número de filiados, seja em número de trabalhos apresentados nas Reuniões Anuais da SBQ (RASBQ).

Em 1998, foi traçado um perfil inicial da DQM, baseado em dados levantados dos trabalhos apresentados nas suas primeiras reuniões, buscando-se identificar membros e áreas de atuação, além de possibilitar uma avaliação global da divisão ${ }^{23}$. Em 2002, quando do aniversário de 25 anos da SBQ, um novo levantamento foi realizado, onde a evolução de aspectos como número de trabalhos, temas de pesquisa, distribuição regional, autoria dos trabalhos e colaborações interinstitucionais foram avaliados, baseados nas reuniões da DQM de 1993 até $2002^{24}$. Uma comparação entre os dados apresentados nestes dois trabalhos (de 1998 e de 2002) surpreende pela grande evolução qualitativa e quantitativa apresentada pela DQM em apenas quatro anos. Estes dois trabalhos são fortemente recomendados para aqueles que tem interesse em informações sobre a criação da DQM e sobre sua evolução, informações estas que não serão consideradas neste texto. Visando um posicionamento em 2007, quando do $30^{\circ}$. aniversário da SBQ, serão apresentados alguns números extraídos da $30^{\mathrm{a}}$. RASBQ ${ }^{25}$, e, quando pertinente, comparados com aqueles obtidos em 2002 e 1998.

$\mathrm{Na} 30^{\mathrm{a}}$. RASBQ, foram apresentados 191 trabalhos na DQM, o que corresponde a 9,2\% do total dos trabalhos apresentados. Este número tem se apresentado aproximadamente constante (em torno 
de $10 \%$ do número total de trabalhos) desde 1999, o que coloca a DQM entre as quatro maiores Divisões da SBQ, em número de trabalhos (comparando-se em 2007, temos como maiores participações: 15,6\% para PN, 11,2\% para QA, 11,2\% para QI e 7,9\% para QO). Os trabalhos apresentados na DQM foram agrupados dentro de algumas temáticas de pesquisa, arbitrariamente classificadas pelo autor deste texto, e encontram-se listadas na Tabela 1. Para a montagem desta Tabela não foram consideradas sobreposições de temas (por exemplo, trabalhos versando sobre nanocompósitos formados por polímeros condutores foram contabilizados no tema "nanomateriais" em detrimento do tema "polímeros condutores"). Nota-se pela Tabela 1 a grande abrangência de temas de pesquisa que vêm sendo desenvolvidos no país, o que reflete o grau de maturidade e consolidação da área. Nota-se também que o tema "nanomateriais" corresponde à maioria dos trabalhos (22,5\% do total), em clara sintonia com a tendência global discutida na seção anterior. Chama a atenção, na Tabela 1, o número reduzido de trabalhos envolvendo modelagem e simulação. Esta baixa interação entre teóricos e experimentais é um dos fatores que requerem atenção, pois um bom trabalho de modelagem e simulação contribui na interpretação de vários fenômenos e pode auxiliar no planejamento de novos experimentos.

O elevado grau de ramificação da Química de Materiais pelas áreas tradicionais da Química pode ser corroborado por uma simples análise dos dados apresentados na Tabela 2. Esta Tabela apresenta um levantamento de trabalhos tipicamente relacionados à Química de Materiais que foram apresentados na $30^{\mathrm{a}}$ RASBQ em outras Divisões que não a $\mathrm{DQM}^{26}$. Nota-se que, com poucas exceções (PN, MD, QB, HQ, BA), há disseminação de trabalhos de Química de Materiais na maioria das divisões da SBQ, em proporções bastante significativas em algumas delas. Foram identificados 311 trabalhos de Química de Materiais diluídos nas diferentes Divisões, que somados aos 191 apresentados na DQM totalizam 502 trabalhos, ou seja, 24,15\% dos trabalhos apresentados na RA de 2007. Estes números, em conjunto com os vários trabalhos apresentados por Químicos de Materiais em encontros científicos de outras associações, como ABPOL, SBPMAT, CBCIMAT e SBF (matéria condensada), possibilitam vislumbrar o tamanho desta área no país, a ponto de a caracterizar como uma das mais dinâmicas dentro da Química.

Uma das preocupações detectadas em 1998 foi a grande concentração regional, particularmente no estado de São Paulo, dos grupos de pesquisa atuantes na área ${ }^{23}$. Em 2002 percebeu-se uma melhora na participação de outros estados ${ }^{25}$, embora com uma distribuição ainda bastante desigual para São Paulo. Pelos dados da reunião de 2007, nota-se claramente uma diminuição nesta desigualdade e a maior distribuição regional dos trabalhos em Química de Materiais. Foram apresentados trabalhos por 42 instituições de 17 estados brasileiros, assim distribuídos: São Paulo (USP, UNICAMP, UNESP, USP-RP, USP-SC, UFSCar, PUC-Campinas, LNLS, USF, UNIFRAN, UFABC, IPEN, Embrapa, UMC), Paraná (UFPR, UEM, UEL, UEPG, UNIOESTE), Minas Gerais (UFMG, UFOP, CDTN, UNIFAL), Rio de Janeiro (UFRJ, UFF, UERJ), Goiás (UFG, UEG), Pernambuco (UFPE, UNICAP), Bahia (UFBA UNEB), Sergipe (UFS), Rio Grande do Sul (UFRGS), Santa Catarina (UFSC), Paraíba (UFPB), Tocantins (UFT), Ceará (UFC), Distrito Federal (UnB), Alagoas (UFAL), Rio Grande do Norte (UFRN), Piauí (UFPI). Na opinião do autor, esta distribuição regional mais homogênea é fruto de vários fatores, dentre os quais: aumento da formação de doutores na área de Química de Materiais, fruto da abertura de programas de pós-graduação com linhas de pesquisa nesta área, a partir do início da década de 90. Estes doutores foram contratados em diferentes instituições do país, nuclearam novos grupos de pesquisa atuantes na área e já estão formando novos doutores, que começam a formar um novo ciclo, em efeito cascata; aumento nas políticas científicas de incentivo para o desenvolvimento regional, que possibilitou a fixação de doutores em instituições com atuação até então incipiente na área; aumento dos recursos disponíveis para C\&T, principalmente no tocante aos fundos setoriais, fundo de infra-estrutura, edital universal etc., que permitiram a criação de infra-estrutura (principalmente relacionada a equipamentos de médio porte) compatível para o desenvolvimento das atividades na área; o advento do portal de periódicos da CAPES, que permitiu que toda instituição de ensino e pesquisa do país tivesse acesso rápido e de qualidade à literatura científica mundial, independente de sua localização regional e da existência prévia de infra-estrutura de biblioteca; a criação das grandes redes interinstitucionais de pesquisa, como os Institutos do Milênio e as redes temáticas de nanotecnologia, que juntamente com programas específicos, como o PROCAD-CAPES, permitiram a mobilidade de pesquisadores e estudantes de pós-graduação entre diferentes instituições e o compartilhamento de equipamentos de caracterização de grande porte; uma migração de pesquisadores e grupos de pesquisa que trabalhavam com outras temáticas para a área de (nano)materiais, fruto da relevância científica e tecnológica da mesma, bem como do aumento do aporte de recursos destinados a esta área.

Tabela 1. Temas relacionados aos trabalhos apresentados na Divisão de Química de Materiais durante a $30^{\mathrm{a}}$. Reunião Anual da SBQ ${ }^{26}$

\begin{tabular}{lcc}
\hline Tema & $\begin{array}{c}\text { Número de } \\
\text { ocorrências }\end{array}$ & $\begin{array}{c}\text { Percentual dos } \\
\text { trabalhos da DQM }\end{array}$ \\
\hline Materiais para sensores & 5 & 2,6 \\
Materiais para células solares, LEDs, dispositivos eletroquímicos & 16 & 15 \\
Materiais adsorventes, porosos, para suporte & 12 & 3 \\
Materiais vítreos, fibras óticas, cristais fotônicos & 25 & 7,8 \\
Materiais para catálise & 10 & 6,3 \\
Polímeros - síntese, caracterização, aplicações & 43 & 1,6 \\
Polímeros condutores - síntese, caracterização, aplicações & 35 & 8,1 \\
Nanomateriais - síntese, caracterização, aplicações & 8 & 5,2 \\
Materiais Inorgânicos - Síntese e caracterização & 5 & 22,5 \\
Caracterização de materiais (espectroscópica, estrutural, eletroquímica) & 3 & 18,3 \\
Modificações estruturais de materiais, reações de intercalação e troca-iônica & 2 & 4,2 \\
Caracterização de superfícies/filmes finos & 4 & 2,6 \\
Materiais magnéticos & 3 & 1,6 \\
Medidas de propriedades & 2 & 1,05 \\
Biomateriais & 2,1 \\
Simulação/modelagem & 1,6 \\
\hline
\end{tabular}


Tabela 2. Trabalhos relacionados à Química de Materiais apresentados em diferentes divisões (exceto a DQM) durante a $30^{\mathrm{a}}$. Reunião Anual da SBQ ${ }^{27}$

\begin{tabular}{|c|c|c|}
\hline Divisão & Temática & Número de ocorrências \\
\hline \multirow[t]{4}{*}{ Ambiental } & Materiais para adsorventes de poluentes (orgânicos e metálicos) & 17 \\
\hline & Materiais catalisadores para descontaminação & 20 \\
\hline & Materiais para separação de metais em efluentes & 4 \\
\hline & & Total $=41(24,4 \%)$ \\
\hline \multirow[t]{4}{*}{ Catálise } & $\begin{array}{l}\text { Materiais para catalisadores sólidos: síntese, caracterização, } \\
\text { modificações estruturais }\end{array}$ & 17 \\
\hline & Materiais para suporte de catalisadores & 16 \\
\hline & Nanocatalisadores: síntese, caracterização, performance & 4 \\
\hline & & Total $=37(64,9 \%)$ \\
\hline \multirow[t]{3}{*}{ Educação } & Novos experimentos para graduação baseados em materiais & 3 \\
\hline & Proposta/abordagem sobre ensino de tópicos relacionados a materiais & 2 \\
\hline & & Total $=5(3 \%)$ \\
\hline \multirow[t]{8}{*}{ Eletroquímica } & Materiais para eletrodos, construção e caracterização de novos eletrodos & 23 \\
\hline & Materiais para suporte de substratos eletroativos & 5 \\
\hline & Materiais para aplicação em células a combustível & 9 \\
\hline & Materiais para sensores eletroquímicos & 6 \\
\hline & Caracterização eletroquímica de materiais & 6 \\
\hline & Síntese eletroquímica de materiais & 6 \\
\hline & Estudo de corrosão em materiais & 6 \\
\hline & & Total $=61(63,5 \%)$ \\
\hline \multirow[t]{6}{*}{ Físico-Química } & Polímeros - Síntese, caracterização, aplicações & 6 \\
\hline & Química de superfície e estudo de adsorção em materiais & 9 \\
\hline & Materiais para sensores e eletrodos & 5 \\
\hline & Materiais metálicos, ligas, estudo de corrosão em materiais & 7 \\
\hline & Outros & 4 \\
\hline & & Total $=31(41,9 \%)$ \\
\hline \multirow[t]{3}{*}{ Fotoquímica } & Utilização de materiais para fotocatalisadores & 5 \\
\hline & Outros & 2 \\
\hline & & Total $=7(20 \%)$ \\
\hline \multirow[t]{7}{*}{ Química Analítica } & Aplicação de planejamento fatorial e análise multivariada na síntese de materiais & 2 \\
\hline & Novos materiais para sensores & 2 \\
\hline & Análise de/em materiais & 5 \\
\hline & Materiais para cromatografia (fase estacionária) & 4 \\
\hline & Novos materiais para eletrodos & 1 \\
\hline & Materiais adsorventes/trocadores iônicos para utilização em Q.A. e extração & 5 \\
\hline & & Total $=19(8,2 \%)$ \\
\hline \multirow[t]{6}{*}{ Química Coloidal } & Preparação/modificação de materiais & 3 \\
\hline & Nanomateriais - síntese, caracterização, aplicações & 4 \\
\hline & Reações, modificações e caracterizações de superfícies de materiais & 4 \\
\hline & Adsorção em materiais & 9 \\
\hline & Filmes finos & 1 \\
\hline & & Total $=21(60 \%)$ \\
\hline \multirow[t]{7}{*}{ Química Inorgânica } & $\begin{array}{l}\text { Reações de modificações em materiais hospedeiros } \\
\text { (intercalação, incorporação, troca-iônica) }\end{array}$ & 7 \\
\hline & Materiais inorgânicos catalisadores heterogêneos & 3 \\
\hline & Síntese de materiais & 18 \\
\hline & Nanomateriais - síntese, caracterização, aplicações & 12 \\
\hline & Reações em superfície de materiais, adsorção e imobilização em materiais & 13 \\
\hline & Outros & 6 \\
\hline & & Total $=59(25,3 \%)$ \\
\hline \multirow[t]{4}{*}{ Química Orgânica } & Síntese de materiais orgânicos e precursores & 4 \\
\hline & Cristais líquidos & 3 \\
\hline & Materiais para suporte e catalisadores & 2 \\
\hline & & Total $=9(5,4 \%)$ \\
\hline \multirow[t]{6}{*}{ Química Tecnológica } & Degradação de materiais & 4 \\
\hline & Adsorção em materiais & 7 \\
\hline & Polímeros & 3 \\
\hline & Cerâmicas & 1 \\
\hline & Outros & 3 \\
\hline & & Total $=18(25 \%)$ \\
\hline Química Teórica & Modelamento/cálculos em materiais & 3 \\
\hline & & Total $=3(6,4 \%)$ \\
\hline
\end{tabular}


A relevância da Química de Materiais no país também pode ser mensurada através de um levantamento sobre os artigos publicados nos dois principais periódicos científicos brasileiros, a Química Nova e o Journal of the Brazilian Chemical Society (JBCS), ambos editados pela SBQ. Nos últimos dois anos foram publicados, em Química Nova, 53 artigos relacionados à Química de Materiais (12,8\% do total), sendo 29 no ano de $2005^{27}$ e 24 no ano de $2006^{28}$. No mesmo período, o JBCS publicou um total de 57 artigos (12,2\% do total), sendo 27 em $2005^{29}$ e 30 em $2006^{30}$.

Em todos os aspectos analisados, a Química de Materiais no Brasil vem apresentando uma evolução qualitativa e quantitativa. A DQM da SBQ, desde a sua criação, vem constantemente estimulando a disseminação dos conceitos, a interação e colaboração entre pesquisadores e a criação de fóruns de debates das grandes questões pertinentes à área, não só através das sessões coordenadas e sessões de painéis das RA's, como também pela realização de minicursos, workshops e palestras variadas. A SBQ, através de sua Divisão de Química de Materiais, é um dos grandes vetores responsáveis pelo sucesso desta área no país.

\section{CONSIDERAÇÕES FINAIS}

A área de Química de (Nano)Materiais é bastante dinâmica, encontra-se em fase de crescimento e, portanto, está longe da estagnação. No Brasil, é possível encontrar grupos trabalhando em Química de Materiais em praticamente todos os Departamentos e Institutos de Química do país, com excelente nível científico, em temáticas variadas e originais, vinculados a diversos programas de pós-graduação e com produção cientifica elevada, crescente e com alta inserção internacional. A despeito desta realidade, alguns desafios ainda precisam ser encarados: i) a comunidade acadêmica ainda se encontra muito distante do setor produtivo, embora um grande avanço tenha sido detectado nesta direção nos últimos anos. Esta interação, absolutamente íntima em países da Europa, no Japão e nos EUA, é crucial para o crescimento econômico do país, e tem a Química de Materiais como importante elo de ligação; ii) com o crescimento fantástico da Química de Materiais e da Nanoquímica, e o número cada vez mais crescente de empregos disponíveis para profissionais com esta formação, são necessários ajustes nos currículos dos cursos de Graduação e Pós-graduação em Química e áreas afins, de modo a introduzir conceitos e habilidades compatíveis com o que se espera destes profissionais; iii) como mencionado anteriormente, uma das peculiaridades da área de Química de Materiais é a sua relação íntima com equipamentos de médio e grande porte, necessários para a caracterização dos materiais. Não se imagina possível que cada instituição no país possua em suas instalações todos os grandes equipamentos. É fundamental que os profissionais aprendam a trabalhar em parceria, através do compartilhamento de infra-estrutura e da disseminação de laboratórios multi-usuários, evitando a concentração de máquinas e equipamentos em poucos centros; iv) o estudo de impactos ambientais, de segurança de trabalho e de disposição de rejeitos, principalmente relacionados aos nanomateriais, ainda é bastante incipiente, e precisa ser incentivado; v) a Química de Materiais é uma sub-área da Química, e como tal deve ser considerada. É a Química que a diferencia das outras ciências de materiais e que a torna tão especial e fascinante. Como já mencionado, a Química de Materiais envolve uma formação específica alicerçada em conhecimentos de físico-química, ligações químicas, reatividade, estado-sólido, espectroscopia etc. Todo este arcabouço de conhecimento deve ser utilizado em sua plenitude no desenvolvimento das atividades e na solução dos problemas inerentes à área. A ausência de uma formação específica, consistente e aprofundada nos aspectos básicos da
Química que dão suporte à Química de Materiais pode levar ao aparecimento de aventureiros e de trabalhos inócuos, cuja comunidade deve saber detectar.

Na edição de 3 de abril de 2000, a revista Chemical and Engineering News anunciava: procuram-se químicos criativos para desenvolverem novos materiais ${ }^{31}$. $\mathrm{O}$ anúncio precedia uma reportagem, na seção de empregos da revista, que abordava uma das áreas com maiores oportunidades de trabalho para profissionais da área de Química. Segundo a reportagem (que apresentava o seguinte texto como subtítulo: Química de Materiais, especialmente em escala nanométrica, é uma área em crescimento em grandes e pequenas empresas), indústrias das mais variadas, desde gigantes como Dow Chemical, Dupont ou IBM, até pequenas empresas encubadas ou iniciantes, estão abrindo cada vez mais vagas para químicos trabalharem na área de materiais. Ainda de acordo com esta reportagem, o enfoque das indústrias baseia-se na realidade inconteste de que estamos sempre à procura de novos materiais, seja para melhorar produtos existentes, seja para fazer produtos que só existem na imaginação - ou ainda não foram sequer imaginados. Químicos de Materiais estão intimamente envolvidos nestas questões. De fato, a Química de Materiais corresponde a um dos caminhos possíveis para se resolver alguns dos grandes problemas do século XXI, como a questão energética (através do desenvolvimento de novos materiais para dispositivos fotovoltaicos e células solares, materiais para eletrodos, catalisadores e eletrólitos em baterias, células a combustível e supercapacitores, materiais para LEDs, materiais para geração e armazenamento de hidrogênio, entre outros) e a questão ambiental (materiais para descontaminação de corpos aquáticos e solos, materiais para dispositivos que zerem ou reduzam significativamente a emissão de $\mathrm{CO}_{2}$, materiais preparados a partir de rejeitos etc.), dentre outras. Além disso, é uma das áreas da Química mais intimamente ligada ao conforto e bem estar dos cidadãos, no sentido de que estes estão, mesmo sem se darem conta, em uma busca incessante por novos materiais, visando (de acordo com a reportagem citada) melhorar os já existentes (garrafas plásticas descartáveis substituindo as retornáveis de vidro como embalagem para refrigerantes, CD's substituindo os LP's que substituíram as fitas K7 para gravação, compósitos poliméricos substituindo metais em automóveis), criar produtos que existiam somente na imaginação (computadores portáteis, "pen-drives", DVDs, câmeras digitais, células solares, plásticos leves e altamente resistentes, janelas inteligentes, as mais variadas próteses humanas, vidros auto-limpantes, TVs de plasma, motores especiais, turbinas de avião, novos pigmentos, materiais mais leves e resistentes para construção civil, adesivos poderosos, entre milhares de outros exemplos), ou ainda criar produtos que nos dias de hoje não são sequer imaginados. Não temos todos os materiais que necessitamos e podemos melhorar (e muito) os que já possuímos. A Química de (Nano)Materiais está fazendo a sua parte.

\section{AGRADECIMENTOS}

À SBQ e aos editores deste suplemento especial de QN pelo convite, ao CNPq pela bolsa de pesquisador, ao CNPq (edital universal), CAPES (Procad), CT-ENERG/CNPq e Rede Nacional de Pesquisa em Nanotubos de Carbono pelo auxílio financeiro, e à Dra. M. M. Oliveira pela leitura crítica e sugestões.

\section{REFERÊNCIAS E NOTAS}

1. Interrante, L. V.; Hampden-Smith, M. J.; Chemistry of Advanced Materials: An Overview, Wiley-VCH: New York, 1998.

2. A imagem da capa frontal da primeira edição da revista pode ser acessada em J. Mater. Chem. 1991,1, X001; DOI: 10.1039/JM99101FX001. 
3. http://www.rsc.org/ScienceAndTechnology/Events/ DefiningMaterialsChemistry.asp, acessada em Agosto 2007.

4. www.iupac.org/projects/2005/2005-001-1-200.html, acessada em Agosto 2007.

5. Askeland, D. R.; The Science and Engineering of Materials, $3^{\text {rd }}$ ed., PWS Publishing Company: Boston, 1994.

6. Allen, G.; J. Mater. Chem. 1991, $1,1$.

7. Wilson, E. K.; Chem. Eng. News 2005, 83, 37.

8. http://www.biphorpigments.com, acessada em Agosto 2007

9. http://www.unicamp.br/unicamp/unicamp_hoje/ju/outubro2006/ ju342pag03.html, acessada em Agosto 2007.

10. Chen, J.; Liu, Y.; Minett, A. I.; Lynam, C.; Wang, J.; Wallace, G. G.; Chem. Mater. 2007, 19, 3595

11. Hench, L. L.; West, J. K.; Chem. Rev. 1990, 90, 33.

12. Menezs, W. G.; Reys, D. M.; Oliveira, M. M.; Soares, J. F.; Zarbin, A. J. G.; Chem. Phys. Lett. 2007, DOI: 10.1016/j.cplett.2007.08.026.

13. Galembeck, F.; Materiais: Progressos e Perspectivas, Academia Brasileira de Ciências: Rio de Janeiro, 1997.

14. Iijima, S.; Nature 1991, 354, 56.

15. Radushkevich, L. V.; Lukyanovich, V. M.; Zurn Fisic. Chim. 1952, $26,88$.

16. Terrones, M.; Annu. Rev. Mater. Res. 2003, 33, 419.

17. Li, W. Z.; Xie, S. S.; Qian, L. X.; Chang, B. H.; Zou, B. S.; Zhou, W. Y.; Zhao, R. A.; Wang, G.; Science 1996, 274, 1701.

18. Pitkethly, M. J.; Nano Today 2003, Dec., 36.

19. National Nanotechnology Initiative Report, 2005, disponível em http:// www.nano.gov/FINAL_PCAST_NANO_REPORT.pdf, acessada em Agosto 2007.

20. http://www.nanotechcongress.com/Fortune-Nanotech.pdf, acessada em Agosto 2007.

21. http://www.chemicalvision2020.org/nanotechnology.html, acessada em Agosto 2007.

22. Estimated energy savings and financial impacts of nanomaterials by design on selected applications in the chemical industry, 2006, disponível em www.chemicalvision2020.org, acessada em Agosto 2007.

23. Alves, O. L.; Quim. Nova 1998, 21, 807.

24. Rubira, A. F.; Zarbin, A. J. G.; Galembeck, F.; Alves, O. L.; Jafelicci Jr, M.; Quim. Nova 2002, 25 (supl. 1), 75.

25. Todos os dados referentes à $30^{\mathrm{a}}$. RASBQ foram coletados diretamente pelo autor, a partir do livro de resumos e do CD contendo os resumos expandidos deste encontro.

26. Para a confecção desta tabela foram analisados todos os trabalhos apresentados na $30^{\mathrm{a}}$ RA. Foram considerados trabalhos relacionados à Química de Materiais aqueles que, na visão do autor, têm a sistemática característica da área, de acordo com os critérios discutidos neste texto. Outro critério utilizado foi considerar que o trabalho poderia naturalmente ser apresentado na DQM, dentro do escopo da Divisão. Trabalhos que poderiam criar controvérsia não foram considerados (por exemplo, apesar de um fármaco ser considerado um material, trabalhos descrevendo diferentes aspectos relacionados aos fármacos não foram considerados, por se entender que estes trabalhos têm sistemáticas diferentes, identificadas com as divisões de QO, PN, MD etc.). Esta tabela expressa a visão do autor e, logicamente, está sujeita a discordâncias. Como tal, tem a pretensão única e exclusiva de ilustrar a penetração da Química de Materiais nas diferentes subáreas da Química, baseado em dados da Química brasileira, que tem na RASBQ seu maior espelho.

27. Pergher, S. B. C.; Oliveira, L. C. A.; Smaniotto, A.; Petkowicz, D. I.; Quim. Nova 2005, 28, 751; Pergher, S. B. C.; Sprung, R.; Quim. Nova 2005, 28 , 777; Bertolini, M. J.; Zaghete, M. A.; Gimenes, R.; Paiva-Santos, C. D.; Palma-Dibb, R. G.; Quim. Nova 2005, 28, 813; Basilio, M. S. V.; Friese, K.; de Lena, J. C.; Nalini, H. A.; Roeser, H. M. P.; Quim. Nova 2005, 28, 822; Gouveia, P. S.; Escote, M. T.; Longo, E.; Leite, E. R.; Carreno, N. L. V.; Fonseca, F. C.; Jardim, R. D.; Quim. Nova 2005, 28, 842; Pinheiro, S. C. L.; Raimundo, I. M.; Quim. Nova 2005, 28, 932; Santos, R. K. S.; Batista, M. S.; Assaf, E. M.; Assaf, J. M.; Quim. Nova 2005, 28, 587; Cardoso, W. D.; Gushiken, Y.; Quim. Nova 2005, 28, 723; Cônsul, J. M. D.; Baibich, I. M.; Benvenutti, E.; Thiele, D.; Quim. Nova 2005, 28, 393; Pergher, S. B. C.; Caovilla, M.; Detoni, C.; Machado, N. R. C. F.; Quim. Nova 2005, 28, 397; Chui, Q. S. H.; Iamashita, C. O.; Bispo, J. M. D.; Quim. Nova 2005, 28, 497; Ferreira, M.; Caetano, W.; Itri, R.; Tabak, M.; Oliveira, O. N.; Quim. Nova 2005, 28, 502; Prado, A. G. S.; Faria, E. A.; Padilha, P. M.; Quim. Nova 2005, 28, 544; Soares, L. E. S.; Rocha, R.; Martin, A. A.; Pinheiro, A. L. B.; Zampieri, M.; Quim. Nova 2005, 28, 229; Coelho, F. D.; Couceiro, P. R. D.; Lopes, A. L.; Fabris, J. D.; Quim. Nova 2005, 28, 233; Nssar, E. J.; Ávila, L. R.; Pereira, P. F. S.; de Lima, O. J.; Rocha, L. A.; Mello, C.; Ciuffi, K. J.; Carlos, L. D.; Quim. Nova 2005, 28, 238; Tagliaferro, G. V.; da Silva, M. L. C. P.; da Silva, G. L. J. P.; Quim. Nova 2005, 28, 250; Cassu, S. N.; Felisberti, M. I.; Quim. Nova 2005, 28, 255;
Jose, N. M.; Prado, L. A. S. D.; Quim. Nova 2005, 28, 281; Millen, R. P.; de Faria, D. L.; Temperini, M. L. A.; Quim. Nova 2005, 28, 289; de Barros, R. D. M.; Ribeiro, M. C.; An-Sumodjo, P. T.; Juliao, M. S. D.; Serrano, S. H. P.; Ferreira, N. G.; Quim. Nova 2005, 28, 317; da Silva, F. D.; Couceiro, P. G. D.; Fabris, J. D.; Goulart, A. T.; Ker, J. C.; Quim. Nova 2005, 28, 5; de Lazaro, R. C.; Longo, E.; Beltran, A.; Sambrano, J. R.; Quim. Nova 2005 28, 10; Wypych, F.; Arizaga, G. G. C.; Quim. Nova 2005, 28, 24; Oliveira, A. C.; Rangel, M. D.; Fierro, J. L. G.; Reyes, P.; Oportus, M.; Quim. Nova 2005, 28, 37; de Souza, A. O.; Rangel, M. D.; Alves, O. L.; Quim. Nova 2005, 28, 46; Spinacé, M. A. D.; De Paoli, M.-A.; Quim. Nova 2005, 28, 65; Vieira, R.; Netto, D. B.; Bernhardt, P.; Ledoux, M. J.; Pham-Huu, C.; Quim. Nova 2005, 28, 42; Oliveira, A. R. M.; Zarbin, A. J. G.; Quim. Nova 2005, 28, 141 .

28. Della, V. P.; Hotza, D.; Junkes, J. A.; de Oliveira, W.; Quim. Nova 2006, 29, 1175; Bizeto, M. A.; Christino, F. P., Tavares, M. F. M; Constantino, V. R. L.; Quim. Nova 2006, 29, 1215; Barreto, W. J., Barreto, S. R. G.; Moreira, I.; Kawano, Y.; Quim. Nova 2006, 29, 1255; Piovesan, E.; Hidalgo, A. A.; Marletta, A.; Veja, M. L.; Ruggiero, R.; Quim. Nova 2006, 29, 916; Beck, R. C. R.; Haas, S. E.; Guterres, S. S.; Re, M. I.; Benvenutti, E. V.; Pohlmann, A. R.; Quim. Nova 2006, 29, 990; Queiroz, S. C. N.; Melo, L. F. C.; Jardim, I. C. S. F.; Quim. Nova 2006, 29, 637; Fechine, G. J. M.; dos Santos, J. A. B; Rabello, M. S.; Quim. Nova 2006, 29, 674; Paschoalino, M. P.; Alfaya, A. A. S.; Yabe, M. J. S.; Gimenez, S. M. N.; Quim. Nova 2006, 29, 699; Fungaro, D. A.; Izidoro, J. D.; Quim. Nova 2006, 29, 735; Sant'Ana, A. C.; Corio, P.; Temperini, M. L. A.; Quim. Nova 2006, 29, 805; Franchetti, S. M.; Marconato, J.C.; Quim. Nova 2006, 29, 811; Mulinari, D. R.; da Silva, G. L. J. P; da Silva, M. L. C. P.; Quim. Nova 2006, 29, 496; Previdello, B. A. F.; de Carvalho, F. R.; Tessaro, A. L., de Souza, V. R.; Hioka, N.; Quim. Nova 2006, 29, 600; de Santana, H.; Zaia, D. A. M., Corio, P.; El Haber, F.; Louarn, G.; Quim. Nova 2006, 29, 194; Souza, E. C.; Ticianelli, E. A.; Quim. Nova 2006, 29, 216; Scotti, R.; Lima, E. C.; Benvenutti, E. V.; Piatnicki, C. M. S.; Dias, S. L. P.; Gushikem, Y.; Kubota, L. T.; Quim. Nova 2006, 29, 208; Martins, L.; Pablo, R.; Pequin, S.; Urquieta-Gonzalez, E. A.; Quim. Nova 2006, 29, 223; Lima, A. J. B.; Cardoso, M. D. G.; Guerreiro, M. C.; Pimentel, F. A.; Quim. Nova 2006, 29, 247; dos Santos, V. C.; Kondo, M. M.; Quim. Nova 2006, 29, 251; de Oliveira, H. P. M.; Cossiello, R. F.; Atvars, T. D. Z.; Akcelrud, L.; Quim. Nova 2006, 29, 277; Martins, L.; Cardoso, D.; Quim. Nova 2006, 29, 358; Andrade, A. L.; Domingues, R. Z.; Quim. Nova 2006, 29, 100; Saron, C., Felisberti, M. I.; Quim. Nova 2006, 29, 124; Azevedo, A. F.; Ferreira, N. G.; Quim. Nova 2006, 29, 129

29. Queiroz, C. A. D.; Pedreira, W .R.; Abrão, A.; da Rocha, S. M. R.; de Vasconcellos, M. E.; Seneda, J. A.; Forbicini, C. A. L. G. D.; Boaventura, G. R.; Pimentel, M. M.; J. Braz. Chem. Soc. 2005, 16, 1191; Beck, R. C. R.; Pohlmann, A. R.; Benvenutti, E. V.; Costa, T. D.; Guterres, S. S.; J. Braz. Chem. Soc. 2005, 16, 1233; Costa, L. C. M.; Araújo, M. H.; Sapag, K.; Sardella, M. F.; Silva, H.; Deiana, A. C.; Lago, R. M.; J. Braz. Chem. Soc. 2005, 16, 899; Westrup, J. L., Fritzen, M. B.; Souza, A. J.; Bedendo, G. C.; Nome, F.; Fiedler, H. D.; J. Braz. Chem. Soc. 2005, 16, 982; Ruiz, V. S. O.; Airoldi, C.; J. Braz. Chem. Soc. 2005, 16, 1030; da Silva, J. E. P.; Temperini, M. L. A.; Córdoba de Torresi, S. I.; J. Braz. Chem. Soc. 2005, 16, 322; Rivera, M.; Alvarez-Toledano, C.; Moreno, A.; Sepúlveda-Sanchez, J. D.; J. Braz. Chem. Soc. 2005, 16, 316; Lima, F. H. B.; Giz, M. J.; Ticianelli, E. A.; J. Braz. Chem. Soc. 2005, 16, 328; Martinez, A.; J. Braz. Chem. Soc. 2005, 16, 337; Castillo, M.; Pina-Luis, G.; Diaz-Garcia, M. E.; Rivero, I. A.; J. Braz. Chem. Soc. 2005, 16, 412; Mayer, I.; Eberlin, M. N.; Tomazela, D. M.; Toma, H. E.; Araki, K.; J. Braz. Chem. Soc. 2005 16, 418; Keller, N.; Vieira, R.; Nhut, J. M.; Huu, C. P.; Ledoux, M. J.; J. Braz. Chem. Soc. 2005, 16, 514; Villegas, R. A. S.; Snato, J. L. D.; de Mattos, M. C. S.; de Aguiar, M. R. M. P.; Guarino, A. W. S.; J. Braz. Chem. Soc. 2005, 16, 565; Martins, L.; Peguin, R. P. S.; Wallau, M.; UrquietaGonzales, E. A.; J. Braz. Chem. Soc. 2005, 16, 589; Codognoto, L. C.; Zanichelli, P. G.; Sernaglia, R. L.; J. Braz. Chem. Soc. 2005, 16, 620; Fajardo, H. V.; Probst, L. F. D.; Valentini, A.; Carrero, N. L. V.; Maciel, A. P.; Leite, E. R.; J. Braz. Chem. Soc. 2005, 16, 607; de Oliveira, A. G.; Giacomelli, F. C.; Giacomelli, C.; Spinelli, A.; J. Braz. Chem. Soc. 2005 16, 131; Splendore, G.; Benvenutti, E. V.; Kholin, Y.; Gushikem, Y.; J. Braz. Chem. Soc. 2005, 16, 147; Silva, E. H.; Etchegaray, A.; Carvalho, R. S. H.; Jubilut, G. N.; Miranda, A.; Nakaie, C. R.; J. Braz. Chem. Soc. 2005, 16, 171; Keller, N.; Vieira, R.; Nhut, J. M.; Pham-Huu, C.; Ledoux, M. J.; J. Braz. Chem. Soc. 2005, 16, 202; Osawa, S. S.; Bertran, C. A.; J. Braz. Chem. Soc. 2005, 16, 251; Acevedo, D. F.; Salavagione, H. J., Miras, M. C.; Barbero, C. A.; J. Braz. Chem. Soc. 2005, 16, 259; Giacomelli, C.; Giacomelli, F. C.; Schmidt, V.; Santana, A. L.; Pires, A. T. N.; Bertolino, J. R.; Spinelli, A.; J. Braz. Chem. Soc. 2005, 16, 9; de Campos, J. D. R.; Buffon, R.; J. Braz. Chem. Soc. 2005, 16, 17; Venâncio, E. C.; Consolin, N.; Constantino, C. J. L.; Martin-Neto, L.; Mattoso, L. H. C.; J. Braz. Chem. 
Soc. 2005, 16, 24; Cossiello, R. F.; Akcelrud, L.; Atvars, T. D. Z.; J. Braz Chem. Soc. 2005, 16, 74; Lazarevic, Z. Z.; Miskovic-Stankovic, V. B.; Kacarevic-Popovic, Z.; Drazic, D. M.; J. Braz. Chem. Soc. 2005, 16, 98.

30. Rosseto R.; dos Santos A. C. M. A.; Galembeck, F.; J. Braz. Chem. Soc. 2006, 17, 1465; Marafon, E.; Lucho, A. M. S.; Francisco, M. S. P.; Landers R.; Gushiken, Y.; J. Braz. Chem. Soc. 2006, 17, 1605; Pereira, D. C.; de Faria, D. L. A.; Constantino, V. R. L.; J. Braz. Chem. Soc. 2006, 17, 1651; Nakagaki, S.; Castro, K. A. D. F.; Machado, G. S.; Halma, M.; Drechsel, S. M.; Wypych, F.; J. Braz. Chem. Soc. 2006, 17, 1672; Miwa, D. W.; Santos, M. C.; Machado, S. A. S.; J. Braz. Chem. Soc. 2006, 17, 1339; Luan, J. F.; Zheng, S. R.; Hão, X. P.; Luan, G. Y.; Wu, X. S.; Zou, Z. G.; J. Braz. Chem. Soc. 2006, 17, 1368; Lavat, A. E.; Baran, E. J.; J. Braz. Chem. Soc. 2006 17, 1436; Mochida, I.; Yoon, S. H.; Qiao, W. M.; J. Braz. Chem. Soc. 2006 17, 1059; Frackowiak, E.; J. Braz. Chem. Soc. 2006, 17, 1074; Béguin, F.; J. Braz. Chem. Soc. 2006, 17, 1083; Bourrat, X.; Langlais, F.; Chollon, G.; Vignoles, G. L.; J. Braz. Chem. Soc. 2006, 17, 1090; de Castro, L. D.; J. Braz. Chem. Soc. 2006, 17, 1096; Lima, L. R. P. D. A.; Rey, A. D.; J. Braz. Chem. Soc. 2006, 17, 1109; Goncalez, V.; Barcia, F. L.; Soares, B. G.; J. Braz. Chem. Soc. 2006, 17, 1117; Veríssimo, C.; Moshkalyov, S. A.; Ramos, A. C. S.; Gonçalves, J. L.; Alves, O.L.; Swart, J. W.; J. Braz. Chem. Soc. 2006, 17, 1124; de Mesquita, J. P.; Martelli, P. B.; Gorgulho, H. D. F.; J.
Braz. Chem. Soc. 2006, 17, 1133; Mendez, M. O. A.; Lisboa, A. C. L.; Coutinho, A. R.; Otani, C.; J. Braz. Chem. Soc. 2006, 17, 1144; de Almeida, C.; Zarbin, A. J. G.; J. Braz. Chem. Soc. 2006, 17, 1151; Forhan, N. A. E.; Fantini, M. C. A.; Pereyra, I.; J. Braz. Chem. Soc. 2006, 17, 1158; da Silva, C. R.; Wallau, M.; Urquieta-Gonzalez, E. A.; J. Braz. Chem. Soc. 2006, 17, 1170; Sucasaire, W.; Matsuoka, M.; Lopes, K. C.; Mittani, J. C. R.; Avanci, L. H.; Chubaci, J. F. D., Added, N.; Trava, V.; Corat, E. J.; J. Braz. Chem. Soc. 2006, 17, 1163; Dias, N. L.; Cardoso, C. X.; de Aquino, H. A.; J. Braz. Chem. Soc. 2006, 17, 935; Martins, R. M.; da Silva, C. A.; Becker, C. M.; Samios, D.; Christoff, M.; Bica, C. I. D.; J. Braz. Chem. Soc. 2006, 17, 944; de Andrade, M. L.; Atvars, T. D. Z.; J. Braz. Chem. Soc. 2006, 17, 1000; Bazito, F. F. C.; Torresi, R. M.; J. Braz. Chem. Soc. 2006, 17, 627; Dias, N. L.; Caetano, L.; do Carmo, D. R.; Rosa, A. H.; J. Braz. Chem. Soc. 2006, 17, 473; Schaffazick, S. R.; Adriana, R. P. A.; Graziela, M. A.; Guterres, S. S.; J. Braz. Chem. Soc. 2006, 17, 562; Suffredini, H. B.; Salazar-Banda, G. R.; Tanimoto, S. T.; Calegaro, M. L.; Machado, S. A. S.; Avaca, L. A.; J. Braz. Chem. Soc. 2006, 17, 257; Ferreira, O. P.; Souza, A. G.; Mendes, J.; Alves, O. L.; J. Braz. Chem. Soc. 2006, 17, 393; de Oliveira, E. C.; Pires, C. T. G. V. M. T.; Pastores, H. O.; J. Braz. Chem. Soc. 2006, $17,16$.

31. Henry, C. M.; Chem. Eng. News 2000, 78 (14), 73. 